\title{
LONG-TERM RESULTS OF HEART VALVE REPLACEMENT WITH THE EDWARDS DUROMEDICS BILEAFLET PROSTHESIS: A PROSPECTIVE TEN-YEAR CLINICAL FOLLOW-UP
}

Bruno K. Podesser, MD

Gudrun Khuenl-Brady, $\mathrm{MD}^{\mathrm{a}}$

Ernst Eigenbauer, $\mathrm{DE}^{\mathrm{b}}$

Suzanne Roedler, MD ${ }^{\mathrm{c}}$

Arno Schmiedberger, MD ${ }^{\mathrm{a}}$

Ernst Wolner, MD ${ }^{\mathrm{a}}$

Anton Moritz, $\mathrm{MD}^{\mathrm{a}}$
Objective: The Edwards Duromedics valve (Baxter Healthcare Corp., Edwards Division, Santa Ana, Calif.) was designed with a self-irrigating hinge mechanism to reduce thromboembolic complications. After good initial clinical results, distribution was suspended in 1988 after reports of valve fracture after 20,000 valves had been implanted. The manufacturer conducted extensive studies to improve the Edwards Duromedics and reintroduced a modified version, which is available as Edwards Tekna. The purpose of the study was the evaluation of long-term results of the original Edwards Duromedics that might be important for the current version, the Edwards Tekna valve. Methods: A prospective clinical 10-year follow-up was performed of 508 patients who underwent valve replacement with the Edwards Duromedics valve in the aortic $(n=268)$, mitral $(n=183)$, and aortic and mitral $(n=56)$ position. Results: The perioperative mortality rate was $6.9 \%$; follow-up was $98 \%$ complete, comprising 3648 patient-years for a mean follow-up of 86 months (range: 33 to 144 months). The actuarial freedom from complications at the 10 -year follow-up and the incidence rate (percent per patient-year) were as follows: late mortality rate, $69.2 \% \pm 2.4 \%$ (3.5\% per patient-year); thromboembolism, $90.7 \% \pm 1.6 \%(0.96 \%$ per patient-year); anticoagulation-related hemorrhage, $87.7 \% \pm 1.7 \%(1.34 \%$ per patient-year); prosthetic valve endocarditis, $96.7 \% \pm 0.09 \%(0.38 \%$ per patient-year); valve-related mortality rate, $89.3 \% \pm 1.6 \%(1.21 \%$ per patient-year); valve failure, $86.2 \% \pm 1.85 \%$ ( $1.54 \%$ per patient-year); and valve-related morbidity and mortality rate, $71.1 \% \pm 2.3 \%(3.2 \%$ per patient-year). Three leaflet escapes were observed (one lethal, two successful reoperations; $99.1 \% \pm \mathbf{0 . 0 5} \%$ freedom, $\mathbf{0 . 0 8} \%$ per patient-year). All patients functionally improved (86\% in New York Heart Association classes I and II), and incidence of anemia was insignificant. Conclusions: These results confirm that the Edwards Duromedics valve shows excellent performance concerning thromboembolism, hemolysis, and functional improvement and will serve as a reference for the last version, the Edwards Tekna valve, where comparable long-term data are currently not available. (J Thorac Cardiovasc Surg 1998;115:1121-9)
$T^{\text {he }}$ he Edwards Duromedics (Baxter Healthcare Corp., Edwards Division, Santa Ana, Calif.) prosthetic bileaflet heart valve was introduced into clin-

From the Departments of Cardiothoracic Surgery, ${ }^{a}$ Medical Statistics, ${ }^{\mathrm{b}}$ and Cardiology, ${ }^{\mathrm{c}}$ all General Hospital, University of Vienna, Vienna, Austria.

Received for publication March 24, 1997; revisions requested May 15, 1997; revisions received Nov. 5, 1997; accepted for publication Nov. 14, 1997.

Address for reprints: Bruno K. Podesser, MD, Department of Cardiothoracic Surgery, General Hospital, University of Vienna, Waehringer Guertel 18-20, 1090 Vienna, Austria.

Copyright (C) 1998 by Mosby, Inc.

0022-5223/98 $\$ 5.00+0 \quad \mathbf{1 2 / 1 / 8 7 6 8 5}$ ical use in 1982; our institution (former II. Department of Surgery, University of Vienna) was one of the primary investigation centers, which started implantation in 1983. After good initial clinical results, two cases of leaflet escape were observed in our institution in 1986; another 10 valve failures occurred world-wide. ${ }^{1,2}$ As a consequence, the valve was withdrawn from the market in 1988 after approximately 20,000 valves had been implanted.

Since market suspension, Edwards CVS Division has conducted extensive studies of the Edwards Duromedics bileaflet valve. After these investigations, the prosthesis has been successfully modified 
Table I. Patient characteristics

\begin{tabular}{lcclc}
\hline & AVR & MVR & DVR & Total \\
\hline No. of patients & 268 & 183 & 56 & 507 \\
Mean age (yrs) & 55 & 53 & 53 & 54 \\
Male/female & $1.8: 1$ & $1: 1$ & $1: 1.3$ & $1: 1$ \\
Atrial fibrillation (\%) & 6 & 77 & 63 & 40 \\
Systemic emboli* (\%) & 6.7 & 23 & 20 & 15 \\
Operative mortality (\%) & 4.9 & 7.1 & 16 & 6.9 \\
Previous cardiac surgery (\%) & 6.3 & 25 & 26.8 & 15 \\
CABG or other additional & 33 & 17 & 14 & 22.5 \\
$\quad$ procedure $(\%)$ & & & &
\end{tabular}

$C A B G$, Coronary artery bypass grafting.

*Percentage of patients with preoperative history of systemic embolism.

and was reintroduced in 1990. The most important improvements are an additional shock absorber in the sewing ring and a more sophisticated quality control of the material. The valve has been available as the Edwards Tekna bileaflet valve since 1993.

This report summarizes experiences with the original Edwards Duromedics valve in a prospective clinical follow-up. We assert that clinical long-term results will be comparable to the modified Edwards Tekna bileaflet valve, especially with respect to mechanical durability, thromboembolism, and possible hemolysis.

\section{Material and methods}

At the II Department of Surgery, University of Vienna, between September 1983 and May 1988, a total of 564 Edwards Duromedics bileaflet prostheses were implanted in 507 patients. Two hundred sixty-eight patients underwent isolated aortic valve replacement (AVR), 183 patients underwent isolated mitral valve replacement (MVR), and 56 patients underwent aortic and mitral double valve replacement (DVR). To assure long-term follow-up, only Austrian citizens or foreign residents in Austria were included in the study protocol.

The cause of the valve disease was as follows: degenerated, calcified valves (51\%); history of rheumatic disease $(30 \%)$; bacterial endocarditis $(7 \%)$; and prosthetic rereplacement $(7 \%)$. In patients with no clear history of rheumatic or other valve disease, the cause was classified as unknown $(5 \%)$. Seventy-seven $(15 \%)$ patients had undergone previous cardiac surgery, and 114 (22.5\%) patients had undergone additional procedures, mostly coronary artery bypass operations. The different valve sizes implanted in aortic and mitral position were as follows: aortic dimension/number of implants $(19 / 15,21$ / 90, 23/109, 25/75, 27/32, 29/3), mitral dimensions/number of implants $(25 / 4,27 / 37,29 / 94,31 / 88,33 / 16)$. Further perioperative patient data are given in Table I.

Operative technique and postoperative patient management. The standard cardiopulmonary bypass technique was used for valve implantations. Myocardial protection was achieved with moderate systemic hypothermia $\left(28^{\circ} \mathrm{C}\right)$, multiple-dose St. Thomas' Hospital crystalloid cardioplegia, and topical cooling with iced saline solution. The prostheses were inserted with 2-0 polyester fiber (Ti-Cron; Davis \& Geck, Danbury, Conn.) pledget-armed mattress sutures. Before surgery, patients received 5000 IU heparin therapy subcutaneously three times a day. Permanent anticoagulation with phenprocoumon was started on postoperative day 4 . The target level of anticoagulation was a thrombotest of 5\% to $15 \%$ (Nycomed Pharma, Oslo, Norway), representing an international normalized ratio of 2.1 to 4.8 .

Follow-up. The study protocol of the present study was designed as a prospective follow-up, but after two instances of leaflet escape from mitral valves, the prosthesis was used only in the aortic position until it was withdrawn from the market. Therefore the study group became imbalanced. At 3 months and every year after surgery, questionnaires were mailed to patients unless they were seen in the outpatient department. From postoperative year 3 onward, the questionnaires were completed and signed by the patients with their general practitioners to improve the accuracy of these forms. General practitioners were also contacted to assess the accurate cause of death in cases where a patient had died at home. Information was available for 498 of the initial 507 patients; thus follow-up was $98 \%$ complete. The cumulative patient follow-up was 3647 patient-years with a mean observation period of 86 months (years/months: AVR 1978/89, MVR 1286/84, DVR 382/82).

Definition of complications and consequences of morbid events. Complications and consequences of morbid events were defined according to the published guidelines for reporting valve-related morbidity and mortality rates after cardiac valvular operations. ${ }^{3}$ Because this follow-up protocol was started in 1983 and already two follow-up studies have been published according to the guidelines dating from 1988, the present study was evaluated according to the 1988 version.

Statistical analysis. Values are presented as the mean \pm standard deviation. Actuarial estimates of morbid events were calculated by the method of Kaplan-Meier life-table analysis (product limit). Ninety-five percent confidence limits for the distribution function were calculated according to the Greenwood formula. ${ }^{4}$ The incidence of complications for the 12-month intervals was determined as the conditional probability of an event. The survivals of an age- and sex-matched normal population were calculated from Austrian life-tables (Oesterreichisches Statistisches Zentralamt, 1995). The Wilcoxon log rank test for equality of survival curves was used to compare the groups.

\section{Results}

Perioperative deaths. Thirty-five of 507 patients died either within the first 30 days after the operation or during the hospitalization in which the operation was performed, resulting in a perioperative mortality rate of $6.9 \%$. Of the perioperative deaths, $36 \%$ of the patients had undergone additional procedures; $30.5 \%$ of the patients had undergone previous cardiac procedures. Fifteen patients 


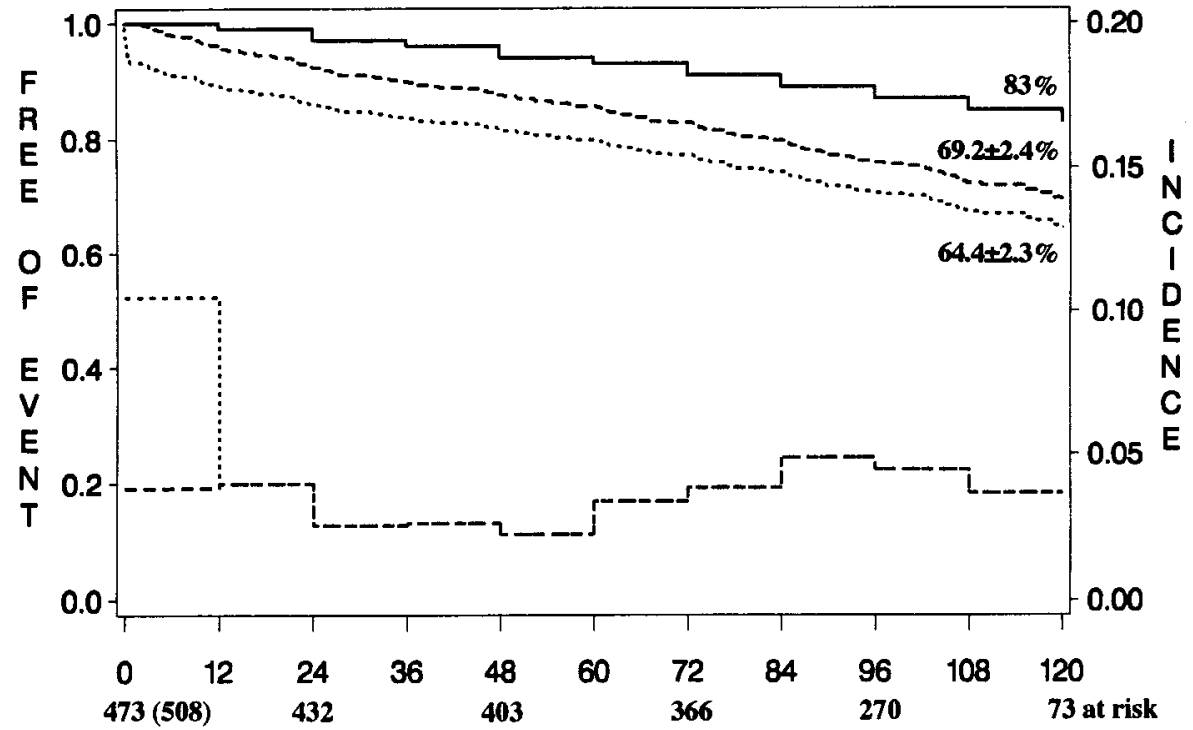

Fig. 1. Ten-year survival with and without operative mortality rates. The upper curve shows the survival probability of the age- and sex-matched Austrian population. Incidences are on the lower part of the graph. Bottom numbers represent months of observation and persons at risk. The solid line represents survival control population; the dashed line represents survival without operative mortality rates; and the dotted line represents survival with operative mortality rates.

died of low cardiac output syndrome; eight patients died of a lethal myocardial infarction; five patients died of septic complications including four patients with acute endocarditis. In four patients, bleeding was the major cause of death, which included two ventricular ruptures. Three patients died of other causes.

Late deaths. By the date of the last follow-up, 125 patients had died. The causes of late death were valve-related in 44 patients. Among these patients, thromboembolism occurred in four patients (two valve thromboses, one cerebral and one mesenteric embolism), and anticoagulation-related bleeding occurred in eight patients. Five patients died of prosthetic valve endocarditis. One patient died of leaflet escape in mitral position 8 years after the operation. The autopsy showed the broken leaflet in the left ventricular outflow tract. Ten patients died of other cardiac diseases (myocardial infarction, arrhythmia). Another 16 patients died suddenly of unknown causes. Cardiac-related death from progressive congestive heart failure was found in 50 patients; noncardiac-related death occurred in 31 patients. An overall survival rate of $69.2 \% \pm 2.4 \%$ (AVR 73.2\% $\pm 3.1 \%$; MVR $64.4 \% \pm 4.1 \%$; DVR $66.4 \% \pm 8.0 \%$ ) was calculated excluding perioperative mortality rates, and $64.4 \% \pm 2.3 \%$ (AVR
$69.6 \% \pm 3.1 \%$ versus MVR $59.84 \% \pm 4.0 \%$ and DVR $55.74 \% \pm 7.5 \% ; p=0.05)$ including perioperative mortality rates. The linearized rate of late deaths after surgery was $3.5 \%$ per patient-year (AVR 3.13\%, MVR 4.19\%, DVR 3.4\%) excluding perioperative mortality rates and $4.5 \%$ per patientyear (AVR 3.79\%, MVR 5.21\%, DVR 5.76\%) including perioperative mortality rates. The survival rate of an age- and sex-matched population according to the Austrian life-tables was estimated (83\% after 120 months, Fig. 1).

\section{Valve-related complications}

Thromboembolism. Thirty-five patients sustained a thromboembolic event. With the exception of the four patients with lethal sequelae, ten patients had embolic episodes that led to permanent neurologic deficits. Overall freedom from thromboembolism, including valve thrombosis, at 10 years was $90.7 \% \pm$ $1.6 \%$ (AVR 90.9\% $\pm 2.2 \%$; MVR $89.4 \% \pm 2.6 \%$; DVR $94.2 \% \pm 4.1 \%$; no significant difference), the overall incidence of thromboembolism was $0.96 \%$ per patient-year (AVR 0.87\%; MVR 1.17\%; DVR $0.52 \%$; Fig. 2).

Anticoagulation-related hemorrhage. Forty-nine patients had anticoagulation-related complications. Gastrointestinal bleeding occurred in 15 patients (one lethal); bleeding from the urogenital system 


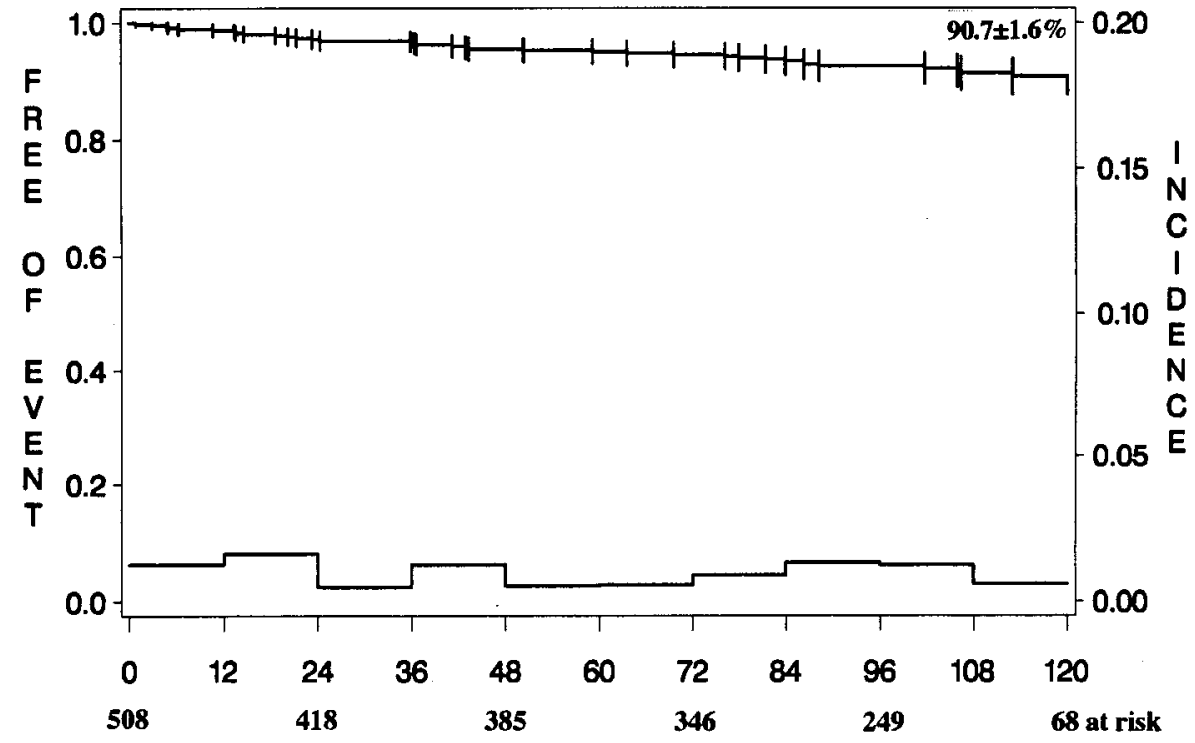

Fig. 2. Event-free rate and yearly incidence of thromboembolic events after 120-month follow-up. Incidences are on the lower part of the graph. Bottom numbers represent months of observation and persons at risk; the solid line represents thromboembolic complications.

occurred in 15 patients; and cerebral bleeding occurred in 9 patients (seven lethal). Ten patients showed other bleeding. Six patients needed surgical intervention to recover. The probability of freedom from anticoagulation-related hemorrhage at 10 years was $87.7 \% \pm 1.7 \%$ (AVR $84.4 \pm 2.6$; MVR $91.0 \pm 2.3$; DVR $86.0 \pm 6.0$; no significant difference), the overall incidence of anticoagulation-related hemorrhage was $1.34 \%$ per patient-year (AVR 1.67\%; MVR 1.09\%; DVR 1.31\%; Fig. 3).

Prosthetic valve endocarditis. Prosthetic valve endocarditis developed in 14 patients. Five patients died of this complication, and three patients underwent successful reoperation. The probability of freedom from prosthetic valve endocarditis at 10 years was $96.7 \% \pm 0.09 \%$ (AVR $97.4 \% \pm 1.05 \%$; MVR $95.4 \% \pm 1.7 \%$; DVR $97.7 \% \pm 2.3 \%$; no significant difference); the incidence of prosthetic valve endocarditis was $0.38 \%$ per patient-year (AVR 0.3\%; MVR 0.54\%; DVR 0.26\%).

Nonstructural dysfunction. All together 17 patients had nonstructural valve dysfunction; a hemodynamically significant paravalvular leak was found in 13 patients, of whom 5 patients had to undergo reoperation, leaving $96.9 \% \pm 0.09 \%$ (AVR $98.3 \%$ $\pm 0.84 \%$; MVR $97.2 \% \pm 1.4 \%$ versus DVR $88.5 \%$ $\pm 4.9 \% ; p=0.01)$ free from this event $(0.36 \%$ per patient-year; AVR 0.2\%; MVR 0.31\%; DVR $1.31 \%)$. Two oversized valves necessitated reopera- tion, and a high transvalvular gradient of $50 \mathrm{~mm} \mathrm{Hg}$ with normal leaflet mobility developed in one patient. In one mitral prosthesis the mural leaflet failed to close intermittently. Although the patient experienced a minor stroke, she did not agree to undergo reoperation. The probability of freedom from nonstructural valve dysfunction at 10 years was $95.8 \% \pm 1.0 \%$ (AVR $97.1 \% \pm 1.1 \%$; MVR $96.4 \%$ $\pm 1.6 \%$ versus DVR $86.3 \% \pm 5.3 \%$; $p=0.01$ ), the incidence of nonstructural valve dysfunction was $0.49 \%$ per patient-year (AVR $0.35 \%$; MVR $0.39 \%$; DVR $1.57 \%$ ).

Structural dysfunction. In two patients a leaflet escape occurred in mitral position (one patient with MVR, one with DVR); both patients underwent successful reoperation, and the embolized leaflets were removed. ${ }^{1}$ As mentioned earlier, one patient died 8 years after the operation of leaflet escape in the mitral position (MVR). The probability of freedom from structural valve dysfunction at 10 years was $99.1 \% \pm 0.05 \%$ (AVR $100 \%$; MVR $98.2 \% \pm$ $1.3 \%$; DVR $97.7 \% \pm 2.3 \%$; no significant difference); the incidence of structural valve dysfunction was $0.08 \%$ per patient-year (AVR $0 \%$; MVR $0.16 \%$; DVR $0.26 \%$ ).

\section{Consequences of morbid events}

Valve-related mortality rates. Forty-four patients died of valve-related complications, as mentioned earlier. The probability of freedom from valve- 


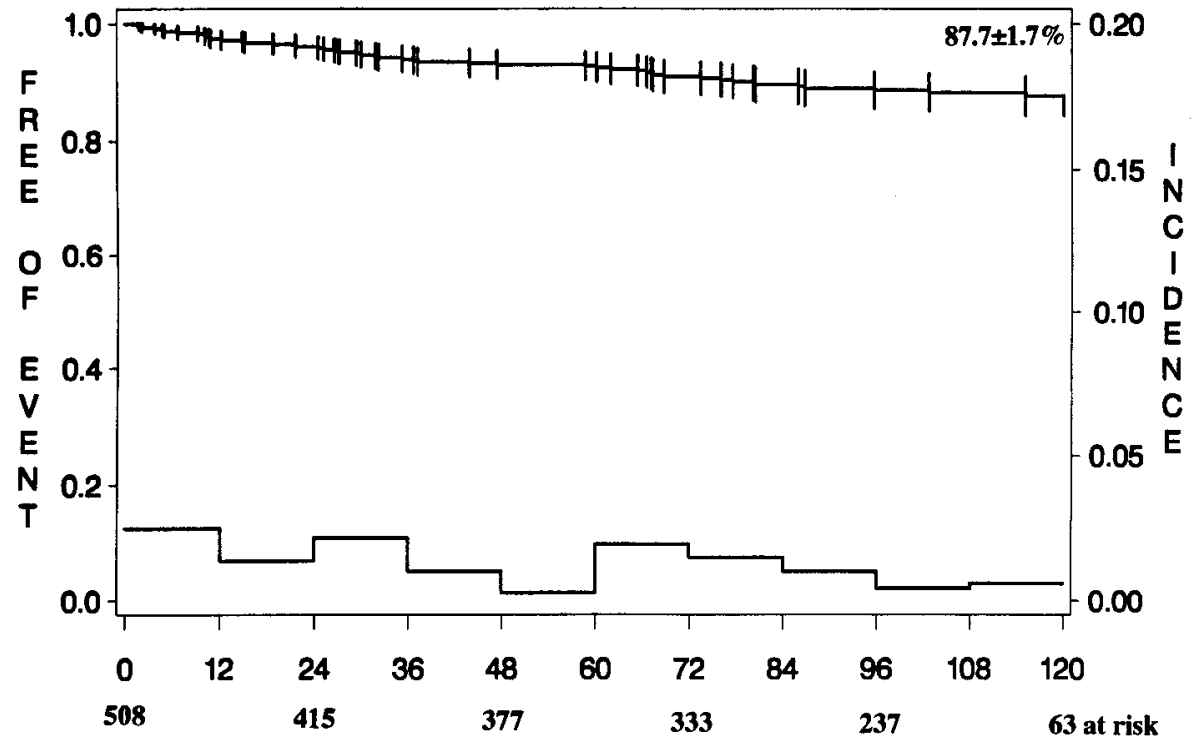

Fig. 3. Event-free rate and yearly incidence of anticoagulation-related hemorrhage after 120-month follow-up. Incidences are on the lower part of the graph. Bottom numbers represent months of observation and persons at risk; the solid line represents anticoagulation-related hemorrhage.

related death at 10 years was $89.3 \% \pm 1.6 \%$ (AVR $92.2 \% \pm 1.8 \%$; MVR $85.3 \% \pm 3.0 \%$; DVR $88.2 \%$ $\pm 5 \%$; no significant difference); the incidence of valve-related death was $1.21 \%$ per patient-year (AVR 0.91\%; MVR 1.63\%; DVR 1.31\%).

Permanent functional impairment. All in all there were 19 cases of permanent functional impairment caused either by stroke, by reduced stress tolerance due to a paravalvular leak, or by impaired valve function. Therefore $95.4 \% \pm 1.3 \%$ (AVR 95.2\% \pm $1.4 \%$; MVR $93.5 \% \pm 3.6 \%$; DVR $96.6 \% \pm 1.5 \%$; no significant difference) of the patients were left free of serious impairment $(0.59 \%$ per patient-year; AVR $0.56 \%$; MVR 0.39\%; DVR 0.78\%).

Valve failure. Valve failure $(1.54 \%$ per patientyear; AVR 1.01\%; MVR 1.94\%; DVR 2.87\%) occurred in 56 patients, including 44 valve-related deaths and 12 reoperations, leaving $86.2 \% \pm 1.8 \%$ of the patients free of event (AVR 91.4\% $\pm 1.9 \%$; MVR $82.6 \% \pm 3.2 \%$; DVR $72.6 \% \pm 7.5 \%$; AVR versus DVR, $p=0.01$; Fig. 4).

All valve-related mortality and morbidity rates. Seventy-one $( \pm 2)$ percent of the patients were free of any valve-related complication (AVR 70.7\% \pm $3.3 \%$; MVR $63.9 \% \pm 4.1 \%$ and DVR $58.9 \% \pm$ $8.4 \%$; no significant difference); the linearized overall incidence was $3.26 \%$ per patient-year (AVR 3.24\%; MVR 4.2\%; DVR 4.19\%; Fig. 4).
Hemolysis. Mechanical hemolysis was found in all patients. It was detected by plasma haptoglobolin, a very sensitive marker, which dropped from $87 \pm 84 \mathrm{mg} / \mathrm{dl}$ after surgery to $19 \pm 25 \mathrm{mg} / \mathrm{dl}$ $(21.5 \pm 31 \mathrm{mg} / \mathrm{dl}, 14.8 \pm 15 \mathrm{mg} / \mathrm{dl}$, and $20 \pm 23$ $\mathrm{mg} / \mathrm{dl}$ for AVR, MVR, and DVR, respectively) 1 year after surgery and remained depressed also at the last laboratory follow-up after 4 years $(15.6 \pm$ $46 \mathrm{mg} / \mathrm{dl}, 21.7 \pm 61 \mathrm{mg} / \mathrm{dl}, 10.7 \pm 27 \mathrm{mg} / \mathrm{dl}$, and $7.7 \pm 5 \mathrm{mg} / \mathrm{dl}$, all, AVR, MVR, and DVR, respectively). Average plasma hemoglobin was $14.5 \pm$ $1.8 \mathrm{gm} / \mathrm{L}(14.9 \pm 1.6 \mathrm{gm} / \mathrm{L}, 14.1 \pm 2 \mathrm{gm} / \mathrm{L}$, and $14 \pm 1.7 \mathrm{gm} / \mathrm{L}$ for AVR, MVR, and DVR, respectively) 1 year and $14.4 \pm 2.0 \mathrm{gm} / \mathrm{L}(14.7 \pm 2 \mathrm{gm} / \mathrm{L}$, $14.1 \pm 2.2 \mathrm{gm} / \mathrm{L}$, and $14 \pm 1.6 \mathrm{gm} / \mathrm{L}$ for AVR, MVR, and DVR, respectively) 4 years after the operation. Plasma lactate dehydrogenase rose from $230 \pm 97 \mathrm{IU} / \mathrm{L}$ to $359 \pm 151 \mathrm{IU} / \mathrm{L}$ (311 \pm 106 $\mathrm{IU} / \mathrm{L}, 398 \pm 160 \mathrm{IU} / \mathrm{L}$, and $460 \pm 171 \mathrm{IU} / \mathrm{L}$ for AVR, MVR, and DVR, respectively) and $354 \pm$ $141 \mathrm{IU} / \mathrm{L}(304 \pm 108 \mathrm{IU} / \mathrm{L}, 390 \pm 140 \mathrm{IU} / \mathrm{L}$, and $453 \pm 181 \mathrm{IU} / \mathrm{L}$ for AVR, MVR, and DVR, respectively). Only one 75-year-old female patient with DVR was left with clinically significant anemia. This anemia was detected 9 years after surgery. No other underlying disease was detected, and the patient underwent successful reoperation with two bioprostheses. 


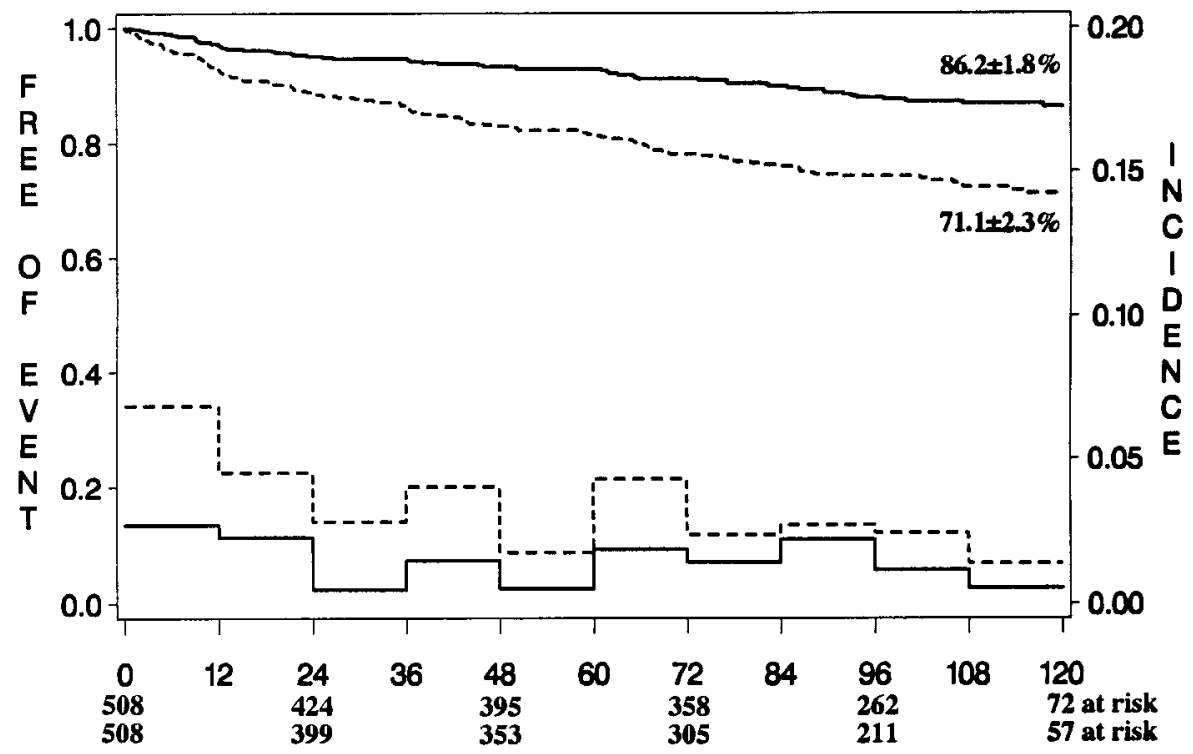

Fig. 4. Event-free rate and yearly incidence of valve failure (solid line) and all valve-related morbidity and mortality rates (dashed line) after 120-month follow-up. Incidences are on the lower part of the graph. Bottom numbers represent months of observation and persons at risk.

Functional improvements. Of the 507 patients for whom follow-up was completed, functional improvement was documented by a marked decrease in New York Heart Association (NYHA) classification, which improved from $3.1 \pm 0.7$ after the operation to $1.5 \pm 0.71$ year after the operation. This improvement was sustained over the follow-up period, leaving $86 \%$ of the patients in NYHA classes I and II (Fig. 5).

\section{Discussion}

Prosthetic valve replacement has remained the most viable alternative for the treatment of severely diseased heart valves..$^{5-7}$ In this study, we summarized our 14 years of experience with the Duromedics Edwards bileaflet prosthesis. The authors are aware that this report presents data that refer, to a certain extent, to a historical valve because the Duromedics Edwards bileaflet prosthesis was suspended from the market in 1988. The reason to present these data is twofold: Approximately 20,000 valves have been implanted, and the modified version of this valve has been successfully introduced to the market. Therefore the present results provide important information on the long-term follow-up of the Edwards Tekna valve because of similarities in the design.

This cohort of patients has been followed up over the past 14 years. In the 4- and 6-year follow-up, the authors were able to show that mechanical hemolysis was subclinical in all patients and that the risk of thromboembolic complications and anticoagulationrelated hemorrhage was comparable to other mechanical valves. ${ }^{8,9}$ In a case report, the successful reoperation of two leaflet escapes in mitral position was reported. ${ }^{1}$ In a Doppler sonographic 5-year follow-up of a subgroup of 145 patients, not one case of impaired left ventricular function was observed. Paravalvular regurgitant jets were mild and clinically insignificant; however, they were more common in aortic than in mitral position. ${ }^{10}$ In a second subgroup of this cohort, various mechanical valves were evaluated with respect to their noise level. The Duromedics Edwards prosthesis had the loudest closing sound of all investigated valves. ${ }^{11}$

The present report confirms the excellent flow characteristics, the data on hemolysis (anemia is insignificantly low), and functional long-term improvement $(86 \%$ of the patients are in NYHA classes I and II). Average survival was $69 \%$, including 16 cases of sudden death. Each cause of sudden death was confirmed by the respective cardiologist or general practitioner who continuously treated and followed the patient's condition. The overall freedom from thromboembolism was $91 \%$, from anticoagulation-related hemorrhage was $88 \%$, and from valve-related morbidity and death was $71 \%$. There were no significant differences between valve 


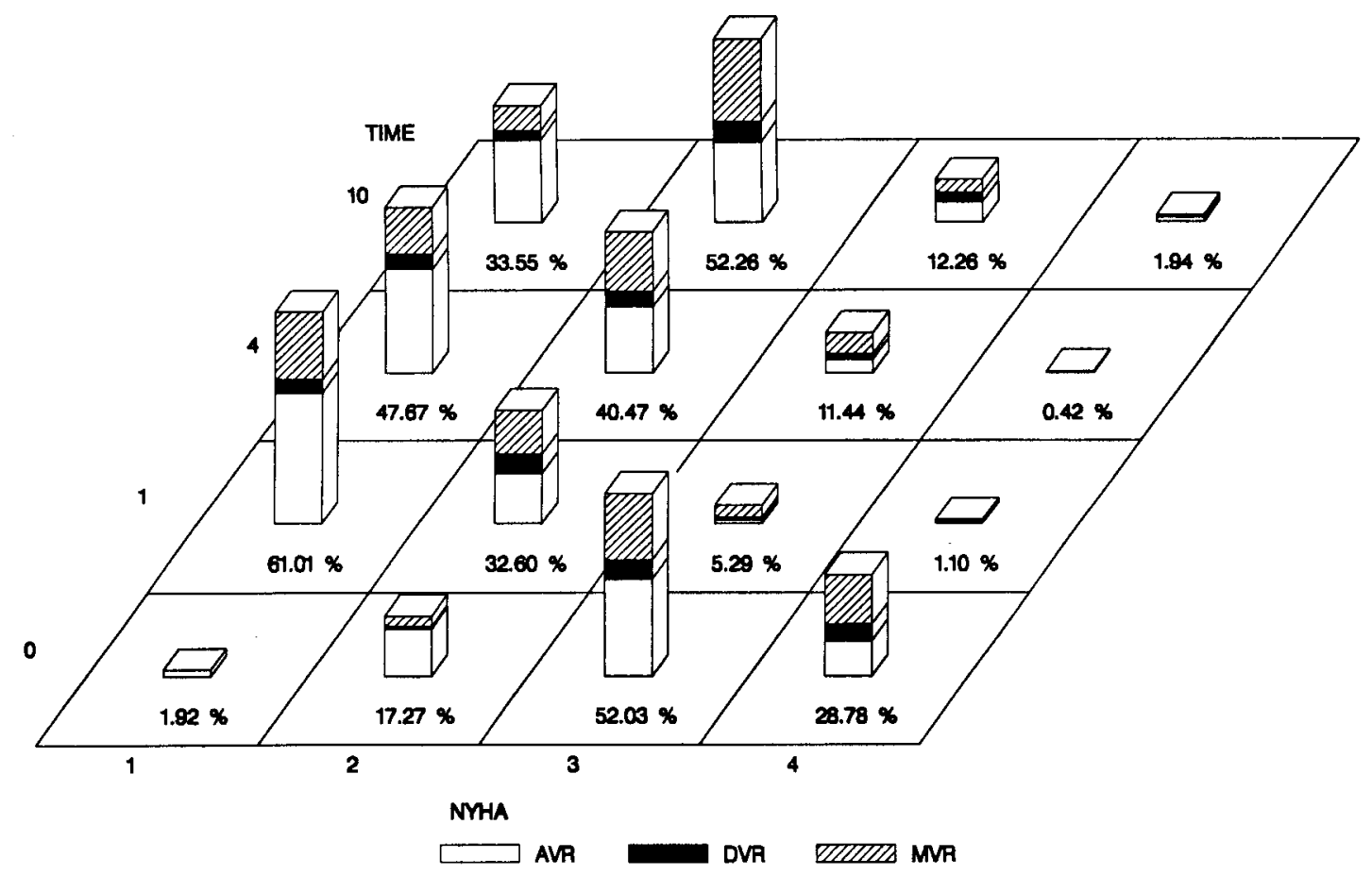

Fig. 5. Physical ability graded according to the NYHA classes (1-4), preoperatively (time $=0$ ), 1 year $($ time $=1), 4$ years $($ time $=4$, ) and 10 years postoperatively $($ time $=10)$. Bars indicate the relative frequency for different valve positions.

positions. However, the incidence of paravalvular leaks was higher in patients with DVR compared with patients with MVR or AVR alone $(1.31 \%$ versus $0.31 \%$ and $0.2 \%$ respectively, $p=0.01$ ). The incidence of nonstructural dysfunction was significantly higher in patients with DVR compared with MVR and AVR (1.57\% versus $0.39 \%$ and $0.35 \%$, respectively, $p=0.01)$. The incidence of valve failure was significantly lower in patients with AVR compared with MVR and DVR (1.01\% vs $1.94 \%$ and $2.87 \%$ respectively, $p=0.01$ ).

Since the last report, the first patient of our cohort died as the result of acute leaflet escape 8 years after MVR. Until 1996, Baxter Corporation (personal communications to B. Podesser on patient implant registry. Irvine, CA: Edwards CVS Division. Baxter Healthcare Corporation, July 1997) reported a total of 46 leaflet escapes; $67 \%$ of these patients survived the event and underwent successful reoperation. According to the Baxter Corporation's patient implant registry, which includes over 11,000 patients, the linearized incidence for structural dysfunction (leaflet escape) is $0.047 \%$ per patient-year compared with $0.08 \%$ per patient-year in our cohort. This represents a freedom from leaflet escape of $99.5 \% \pm 0.08 \%$ or $99.1 \% \pm 0.05 \%$, respectively. The authors believe that the size of the study population $(n=507)$ is the reason for this discrepancy. A recommendation for an elective rereplacement of the Edwards Duromedics valve, based on these data, cannot be given, especially, when the operative mortality rate of a redo operation in mitral position is taken into account. ${ }^{12}$ This is in contrast to the Björk-Shiley CC prosthesis (Shiley, Inc., Irvine, Calif.), where the actuarial incidence of structural valve failure among a number of valves with a certain diameter and date of production was $12.5 \%$ and prophylactic rereplacement for this selected group was recommended. ${ }^{13}$

The data from Baudet and associates, ${ }^{14}$ reporting an 8-year retrospective follow-up on the Edwards Duromedics valve in 257 patients, show a higher rate of survival: Overall actuarial survival was 90\%; survival in aortic position was $86 \%$, in mitral position was $95 \%$, and in DVR was $89 \%$. On the one hand a lower overall incidence of thromboembolic events $(0.7 \%$ per patient-year) and anticoagulationrelated hemorrhage $(0.95 \%$ per patient-year) might be one reason for this discrepancy; on the other hand the retrospective design of the study, where 
data were not accumulated continuously but 3 to 8 years after the implantation could be responsible for the different observations. Finally, also the significantly smaller number of patients must be mentioned.

The low incidence of thromboembolism and anticoagulation-related hemorrhage in the present study is also confirmed by the data from a metaanalysis in patients with mechanical valve prostheses. ${ }^{15}$ In contrast, Fradet and associates ${ }^{6}$ showed in a 10 -year follow-up that only $65 \%$ of patients with mechanical valves were free of thromboembolic events versus $80 \%$ of patients with biologic valves. However, their results might be partly explained by the heterogeneous group of different mechanical prostheses. This is especially important because the curved areas of the Duromedics Edwards prosthesis are known for their hydrodynamic superiority in comparison to plane bileaflet valves. ${ }^{14}$ Finally, data from a 10-year follow-up of another bileaflet valve, the St. Jude Medical valve (St. Jude Medical, Inc., St. Paul, Minn.) are available. Aoyagi and associates $^{5}$ present the data from 908 patients. Overall survival including early death was higher than in our cohort ( $81 \%$ for AVR, $80 \%$ for MVR, and $80 \%$ for DVR), and the incidence of anticoagulation-related hemorrhage was lower than in our cohort $(0.4 \%$, $0.3 \%$ and $0.5 \%$ for patients with AVR, MVR, and DVR, respectively). But the incidence of thromboembolism was higher than in our cohort (1\% in AVR, $1.1 \%$ in MVR, and $1.3 \%$ in DVR). There were almost no differences in the incidence of prosthetic valve endocarditis and nonstructural dysfunction $(0.4 \%, 0.03 \%$, and $0.3 \% ; 0.4 \%, 0.2 \%$, and $0.2 \%$; AVR, MVR, and DVR, respectively). No case of structural dysfunction occurred whereas three cases of leaflet escape were found in our cohort. The freedom from valve-related death was slightly higher $(88 \%, 91 \%$, and $84 \%$ for AVR, MVR, and DVR, respectively); the freedom from all complications was slightly lower than in our cohort (75\%, $74 \%$, and $81 \%$ for AVR, MVR, and DVR, respectively). Significant hemolysis occurred in eight patients with St. Jude Medical valves in mitral position; five of these patients died of the sequelae of hemolysis. In contrast, no patient with a Edwards Duromedics valve died because of hemolysis; one patient with DVR had severe hemolysis and underwent successful reoperation. Functionally, $98 \%$ of the patients were in NYHA class I or II. All in all these data from the St. Jude Medical valve suggest a higher overall survival with lower incidence of anti- coagulation-related hemorrhage and no structural dysfunction but a higher incidence of thromboembolic events and hemolysis.

The first data on the currently available Edwards Tekna bileaflet valve are promising with respect to valve-sound loudness and cavitation in comparison with the original Edwards Duromedics and other mechanical valves. ${ }^{16,17}$ Also, the energy loss and leakage volumes were low under static and in pulsatile flow for the Edwards Tekna valve in comparison to other mechanical valves. ${ }^{18}$

In summary, this 10-year follow-up confirms the authors' previous clinical findings with the Edwards Duromedics bileaflet valve: (1) low morbidity as far as thromboembolism, valve thrombosis, and hemolysis are concerned; (2) long-lasting functional improvement; and (3) the possibility of late and lethal leaflet escape. The structural failure of the Edwards Duromedics valve led to readjustment of material porosity and redesign; the currently available last evolution of this valve, the Edwards Tekna, has the superior properties of the original valve and the improved requirements in material. The current Edwards Tekna valve was introduced in 1993. Therefore these data of the original Edwards Duromedics bileaflet valve are not just of historical interest but are the only long-term results applicable to the Edwards Tekna valve until updated results on this valve become available.

\section{REFERENCES}

1. Klepetko W, Moritz A. Leaflet fracture in Duromedics Edwards bileaflet valves. J Thorac Cardiovasc Surg 1989;97: 90-4.

2. Radlick P. Suspension of marketing of Edwards Duromedics bileaflet valve models 3160 and 9120 all sizes [abstract]. Important Product Information 1-2. Irvine, CA: Edwards CVS Division, Baxter Healthcare Corporation, May 1988.

3. Edmunds LH Jr, Miller DC, Cohn LH, Clark RE, Weisel RD. Guidelines for reporting morbidity and mortality after cardiac valvular operations. J Thorac Cardiovasc Surg 1988; 96:351-3.

4. Cary NC. The lifetable procedure. In: SAS users guide statistics, version 5. SAS Institute, Inc. 1985;529-57.

5. Aoyagi S, Oryoji A, Nishi Y, Tanaka K, Kouga K, Oishi K. Long-term results of valve replacement with the St. Jude Medical valve. J Thorac Cardiovasc Surg 1994;108:1021-9.

6. Fradet GJ, Jamieson WRE, Abel JG, et al. Clinical performance of biological and mechanical prostheses. Ann Thorac Surg 1995;60:453-8.

7. Akins CW, Caroll DL, Buckley MJ, Dagger WM, Hilgenberg $\mathrm{AD}$, Austen WG. Late results with Carpentier-Edwards porcine bioprosthesis. Circulation 1990;82(Suppl):IV65-74.

8. Moritz A, Klepetko W, Khuenl-Brady G, et al. Four year follow-up of Duromedics Edwards bileaflet valve prostheses. J Cardiovasc Surg 1990;31:274-82. 
9. Moritz A, Klepetko W, Roedler S, et al. Six-year follow-up after heart valve replacement with the Edwards Duromedics bileaflet prosthesis. Eur J Cardiothorac Surg 1993;7:84-90.

10. Globits S, Roedler S, Moritz S, et al. Doppler sonographic evaluation of the Duromedics Edwards bileaflet valve at five-year follow up. J Heart Valve Dis 1993;2:665-70.

11. Moritz A, Steinseifer U, Kobinia G, et al. Closing sounds and related complaints after heart valve replacement with St. Jude Medical, Duromedics Edwards, Björk-Shiley Monostrut, and Carbomedics prostheses. Br Heart J 1992;67: 460-5.

12. Braunwald E. Valvular heart disease. In: Braunwald E, editor. Heart disease. 5th ed. Philadelphia: WB Saunders; 1995. p. 1007-28.

13. Lindblom D, Rodriguez L, Björk VO. Mechanical failure of the Björk-Shiley valve. J Thorac Cardiovasc Surg 1989;97:95-7.
14. Baudet E, Roques X, McBride J, Panes, Grimaud JP. A 8-year follow-up of the Edwards-Duromedics bileaflet prosthesis. J Cardiovasc Surg 1995;36:437-42.

15. Cannegieter SC, Rosendaal FR, Briet E. Thromboembolic and bleeding complications in patients with mechanical heart valve prostheses. Circulation 1994;89:635-41.

16. Erickson RL, Thulin LI, Richard GJ. An in-vitro study of mechanical heart valve sound loudness. J Heart Valve Dis 1994;3:330-4.

17. Guo GX, Adlparvar P, Howanec M, Roy J, Kafesjian R, Kingsbury C. Effects of structural compliance on cavitation threshold measurements of mechanical heart valves. J Heart Valve Dis 1994;3(suppl):77-83.

18. Reul H, van Son JAM, Steinseifer U, et al. In vitro comparison of bileaflet aortic heart valve prostheses. J Thorac Cardiovasc Surg 1993;106:412-20. 